\title{
Aortic arch repair with a working beating heart in premature infants
}

\author{
Kozo Ishino, MD, and Shunji Sano, MD, Okayama, Japan
}

$\mathrm{P}$ rimary repair of aortic arch obstructions and associated cardiac anomalies is a surgical challenge in premature infants. The fragility of these patients, coupled with potentially long periods of myocardial ischemia for intracardiac repair, make it important for survival to avoid or minimize the use of total circulatory arrest. In this article we describe a technique for extended aortic arch anastomosis with selective cerebral perfusion and a working beating heart that has been successfully performed in 4 premature infants weighing less than $2000 \mathrm{~g}$.

\section{Operative Technique and Outcome}

Arterial pressure monitoring lines were placed in the right radial and femoral arteries. Through a midline sternotomy, the thymus gland was excised. The head vessels were exposed and looped with tourniquets. A 2.0-mm angled cannula (Stöckert GmbH, Freiburg, Germany) was directly inserted into the innominate artery. A single venous cannula was placed in the right atrial appendage, and cardiopulmonary bypass (CPB) was established. Another 8F flexible cannula (Kurarey, Co, Ltd, Tokyo, Japan) was introduced at the ductus arteriosus into the descending aorta and was then $\mathrm{Y}$ connected to the arterial CPB perfusion circuit (Figure 1, A). The ductus arteriosus was immediately ligated and transected just proximal to the arterial cannulation site to obtain better exposure of the descending aorta. In case of coarctation of the aorta, the isthmus was also ligated and divided. At a flow rate of $150 \mathrm{~mL}$. $\mathrm{kg}^{-1} \cdot \min ^{-1}$, the patient was cooled to a nasopharyngeal temperature of $34^{\circ} \mathrm{C}$. At this stage, the ascending aorta was crossclamped. When both ventricles were adequately kept loaded (usually right atrial pressures of 4-6 mm Hg), the heart ejected to maintain coronary circulation and beat at a constant rate without changes on the electrocardiogram. Ventilation was maintained with $100 \%$ oxygen to secure return of oxygenated blood to the left ventricle, regardless of the existence of an intracardiac left-right communication.

In patient 2 aortic root pressures measured 40 to $50 \mathrm{~mm} \mathrm{Hg}$, and the oxygen tension of blood obtained from the aortic root was greater than $200 \mathrm{~mm} \mathrm{Hg}$. After removal of the ductal cannula, the

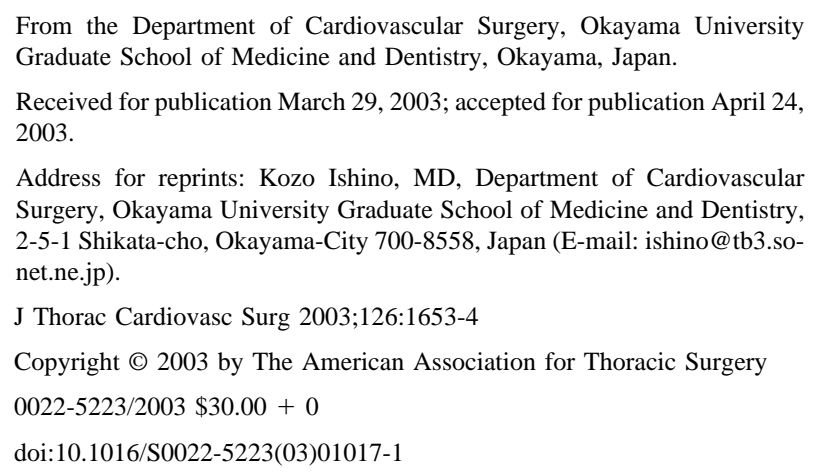

descending aorta was clamped, and ductal tissue was excised. All neck vessels were snared, and the innominate artery was perfused to keep a radial pressure of 30 to $45 \mathrm{~mm} \mathrm{Hg}$. With continuous cerebral perfusion and a working beating heart, the aortic arch was opened inferiorly into the proximal aorta, and the descending aorta was anastomosed to this opening in an end-to-side fashion with 8-0 polypropylene continuous sutures (Figure 1,B). After completion of the extended arch repair, the aortic clamp and neck vessel snares were removed, and full-flow bypass was resumed. The arterial cannula was repositioned to the ascending aorta (Figure 1, C) to prevent maldistribution of CPB flow. Additional procedures included pulmonary artery banding in 1 patient, division and suture closure of the aortopulmonary window in 1 patient, and patch closure of a ventricular septal defect in 2 patients. The results are summarized in Table 1.

\section{Discussion}

Hypothermic total circulatory arrest, a commonly used perfusion strategy for aortic arch repair in neonates, prolongs myocardial ischemia and might be associated with cerebral dysfunction, regardless of its duration. In 1990, Sano and Mee ${ }^{1}$ introduced an isolated myocardial perfusion technique by using an aortic root cannula to reduce myocardial ischemia. Since 1996, we have used innominate artery perfusion in patients undergoing an extended aortic arch reconstruction. Distal arch anastomosis is performed with continuous cerebral and myocardial perfusion by clamping the arch just distal to the innominate artery. ${ }^{2}$ By using this method, however, a short period of cardioplegic arrest is necessary to complete a proximal anastomosis. Recently, Lim and colleagues ${ }^{3}$ reported a combined perfusion technique using dual arterial cannulas; one was placed into the innominate artery and the other into the aortic root. By snaring the innominate artery and crossclamping the ascending aorta, they performed an extended end-to-side anastomosis with continuous cerebral perfusion and a nonworking beating heart. Although their perfusion technique is similar to ours described here, placement of the aortic root cannula can be hazardous, particularly in small infants.

The results of the present series demonstrate that when both ventricles are properly loaded, the heart keeps beating, with the ascending aorta crossclamped. This novel technique not only enables the extended arch anastomosis without cessation of brain and myocardial perfusion but also provides excellent exposure of the ascending aorta and entire aortic arch, even in infants weighing less than $2000 \mathrm{~g}$. The most important issue is related to a CPB technique to maintain a working beating heart. We adjusted the preload on the ventricles according to the electrocardiogram, but cardiac dysfunction did not occur in any of the 4 patients postoperatively. Further investigation is necessary to elucidate the relationship between ventricular preloads and aortic root pressure or coronary blood flow to make on-pump aortic surgery with a working beating heart safer. 


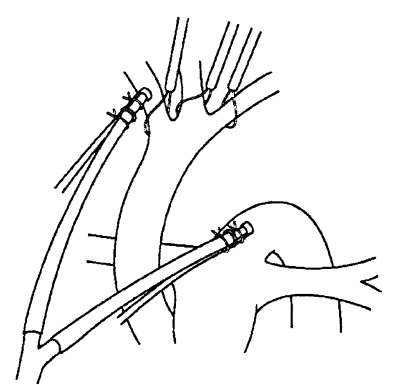

A

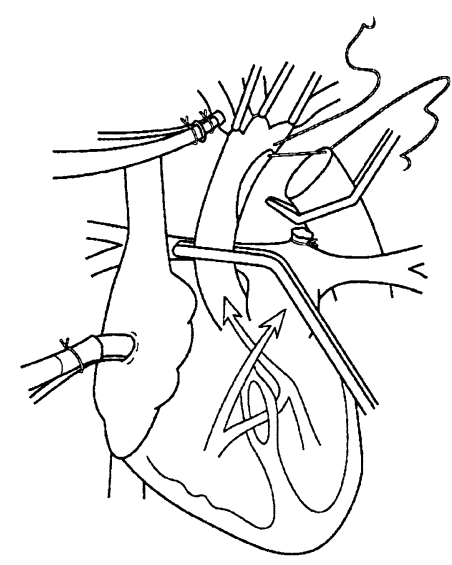

B

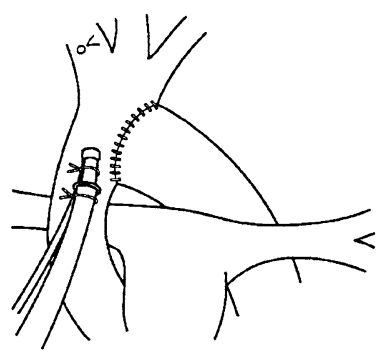

C

Figure 1. A, Arterial cannulas for CPB are inserted into the innominate artery and the descending aorta from the ductus arteriosus. $B$, The ascending aorta is crossclamped, and the heart ejects to maintain coronary circulation. An extended aortic arch anastomosis is performed with continuous cerebral perfusion and a working beating heart. $C$, After completion of the aortic arch repair, the arterial cannula is repositioned to the ascending aorta.

TABLE 1. Patient profiles and surgical outcomes

\begin{tabular}{|c|c|c|c|c|c|c|c|c|}
\hline Patient no. & Age (d) & Weight (g) & Diagnosis & Procedure & $\begin{array}{l}\text { WBH time } \\
\text { (min) }\end{array}$ & $\begin{array}{l}\text { Myocardial } \\
\text { ischemic time } \\
\text { (min) }\end{array}$ & $\begin{array}{l}\text { CPB time } \\
\text { (min) }\end{array}$ & Outcome \\
\hline 1 & 11 & 1840 & $\begin{array}{l}\text { CoA, Hypoarch, } \\
\text { CAVSD, CAVVR }\end{array}$ & Arch repair & 9 & 0 & 81 & Alive \\
\hline 2 & 31 & 1730 & CoA, VSD & $\begin{array}{l}\text { Arch repair } \\
\text { VSD closure }\end{array}$ & 20 & 42 & 156 & Alive \\
\hline 3 & 22 & 1270 & $\mathrm{IAA}(\mathrm{A}), \mathrm{APW}$ & $\begin{array}{l}\text { Arch repair } \\
\text { APW repair }\end{array}$ & 10 & 0 & 81 & Alive \\
\hline 4 & 9 & 1800 & CoA, VSD & $\begin{array}{l}\text { Arch repair } \\
\text { VSD closure }\end{array}$ & 15 & 27 & 95 & Alive \\
\hline
\end{tabular}

WBH, Working beating heart; $C o A$, coarctation of the aorta; CAVSD, complete atrioventricular septal defect; CAVVR, common atrioventricular valve regurgitation; $V S D$, ventricular septal defect; $I A A(A)$, interruption of the aortic arch; $A P W$, aortopulmonary window.

\section{References}

1. Sano S, Mee RBB. Isolated myocardial perfusion during arch repair. Ann Thorac Surg. 1990;49:970-2.

2. Ishino K, Kawada M, Irie H, Kino K, Sano S. Single-stage repair of aortic coarctation with ventricular septal defect using isolated cerebral and myocardial perfusion. Eur J Cardiothorac Surg. 2000;17:538-42.

3. Lim C, Kim WH, Kim SC, et al. Aortic arch reconstruction using regional perfusion without circulatory arrest. Eur J Cardiothorac Surg. 2003;23:149-55. 